\title{
Effect of Achilles tendon on kinematic coupling relationship between tarsal bones: a pilot finite element study
}

\author{
Song-Jian $\mathrm{Li}^{1+}$, Lei Tang ${ }^{2 \dagger}$, Li Zhao ${ }^{3}$, Cheng-Long Liu' and Yu-Bin Liu ${ }^{1,3^{*}}$ (D)
}

\begin{abstract}
Background: The procedure of percutaneous Achilles tenotomy (PAT) is an important component of the Ponseti method. However, few studies reported the influence of Achilles tendon on kinematic coupling relationship between tarsal bones. The purpose of present study was to demonstrate the effect of Achilles tendon on the kinematic coupling relationship between tarsal bones, and to illustrate how kinematic coupling relationship between tarsal bones works in term of finite element analysis.

Methods: A three-dimensional finite element model of foot and ankle was constructed based on the Chinese digital human girl No.1 (CDH-G1) image database using the software of mimics, Geomagic studio, HyperMesh, and Abaqus. The last manipulation of the Ponseti method before the procedure of PAT was simulated. The talus head and the proximal tibia and fibula bone were fixed in all six degrees of freedom, and the outward pressure was added on the first metatarsal head to investigate the kinematic coupling relationship between tarsal bones.

Results: The least relationship of kinematic coupling between tarsal bones was found in calcaneus. Stress concentration was mainly observed at the navicular, talus and the medial malleolus. The difference in displacement of the navicular was only found with the Achilles tendon stiffness of $0 \mathrm{~N} / \mathrm{mm}$ and others. No difference in the navicular displacement was found in the stiffness of Achilles tendon between 40,80, 200,400, and $1000 \mathrm{~N} / \mathrm{mm}$. The maximum displacement of navicular was observed at the ankle position of PF- $20^{\circ}$ (plantar flexion- $20^{\circ}$ ). The difference in displacement of the navicular was greater at the ankle position of PF- $20^{\circ}$ with the Achilles tendon stiffness of $0 \mathrm{~N} / \mathrm{mm}$ than that at the ankle position of PF- $40^{\circ}$ with the Achilles tendon stiffness of $40 \mathrm{~N} / \mathrm{mm}$.

Conclusions: Based on the findings from this study, it was demonstrated that the Achilles tendon existence or not and ankle position had great influence, while increased stiffness of Achilles tendon had no influence on kinematic coupling relationship between tarsal bones. For the cases with severe equinus, earlier implementation of PAT procedure (with the purpose of release the Achilles tendon and reduce the degree of ankle plantar flexion) may be beneficial to the deformity correction.
\end{abstract}

Keywords: Achilles tendon, Kinematic coupling, Tarsal bones, Finite element study

\footnotetext{
*Correspondence: medlyb@163.com

${ }^{\dagger}$ Song-Jian Li and Lei Tang contributed equally to this article, and should be considered the co-first author.

'Department of Orthopaedics, Zhujiang Hospital of Southern Medical

University, Guangzhou 510280, China

${ }^{3}$ Ying-Hua Medical Group of Bone and Joint Healthcare in Children, Shanghai 200092, China

Full list of author information is available at the end of the article
}

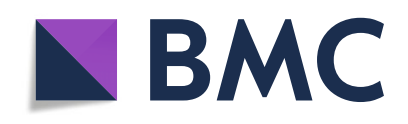

(- The Author(s). 2020 Open Access This article is licensed under a Creative Commons Attribution 4.0 International License, which permits use, sharing, adaptation, distribution and reproduction in any medium or format, as long as you give appropriate credit to the original author(s) and the source, provide a link to the Creative Commons licence, and indicate if changes were made. The images or other third party material in this article are included in the article's Creative Commons licence, unless indicated otherwise in a credit line to the material. If material is not included in the article's Creative Commons licence and your intended use is not permitted by statutory regulation or exceeds the permitted use, you will need to obtain permission directly from the copyright holder. To view a copy of this licence, visit http://creativecommons.org/licenses/by/4.0/. The Creative Commons Public Domain Dedication waiver (http://creativecommons.org/publicdomain/zero/1.0/) applies to the data made available in this article, unless otherwise stated in a credit line to the data. 


\section{Background}

Specific maneuver is one of the core components of the Ponseti method, which has been widely applied for the management of congenital clubfoot [1-4]. The kinematic coupling relationship between tarsal bones was the basis for simultaneous correction of multiple deformity components including cavus, equinus, varus, and adductus [3-6]. During the Ponseti manipulation, the thumb is placed on the lateral aspect of the talus head as a fulcrum while outward pressure is exerted on the first metatarsal and first cuneiform [3, 7]. When the forefoot is abducted laterally, the anterior portion of the calcaneus will be displaced outward underneath the head of the talus, and thus the varus will be corrected simultaneously. The realignment of the calcaneocuboid, the talocalcaneonavicular, and the posterior talocalcaneal joints is produced by means of the kinematic coupling relationship between tarsal bones $[5,6]$.

In anatomy, Achilles tendon connected the soleus and gastrocnemius muscles to the calcaneus to allow plantar flexion of the foot at the ankle. Percutaneous Achilles tenotomy (PAT) is an important component of the Ponseti method. It is indicated when $15^{\circ}$ of ankle dorsiflexion is not obtained after other deformities fully corrected $[3,4,8]$. The reported success rate following PAT ranged from 73 to $100 \%$ [8-10], and there are still left many patients who probably do not respond adequately to the procedure of PAT. In our reported study, the initial correction rate was only $87 \%$ using PAT procedure [1]. Few papers reported the management of these "failed" PAT patients, as the correction was different from the primary cases [11]. Surgical options, such as posteromedial releases [12], gastrocsoleus fascial release, Achilles Tendon lengthening [13], and various osteotomy, were reported according to age and severity of deformity. Mehtani et al. [14] have described a "modified Ponseti method" for achieving better ankle dorsiflexion in neglected children. Agarwal et al. [15] reported the "extended Ponseti method" of continued stretching casts with a weekly change for a further 3 weeks for failed tenotomy in idiopathic clubfeet. All the reported "modified Ponseti protocol" showed good results in salvaging failed tenotomy cases. However, no studies reported the underlying cause for the "failed" PAT patients and explore the deep effect of Achilles tendon on Ponseti maneuver. As the core principle of the Ponseti method, no studies reported the influence of Achilles tendon on kinematic coupling relationship between tarsal bones. In present study, three-dimensional finite element model was established to explore the effect of Achilles tendon on the kinematic coupling relationship between tarsal bones while outward pressure was exerted on the first metatarsal. We aimed to explore how kinematic coupling relationship between tarsal bones works and illustrate the stress and displacement distribution for tarsal bones when outward pressure was added. Also, the clubfoot after initial correction can be considered the normal foot $[1,2,5]$. We built a normal model of foot and ankle to clarify the relative motion and displacement between tarsal bones when outward pressure was added on the first metatarsal. We hypothesized that the Achilles tendon plays an important role in maintaining the effectiveness of kinematic coupling relationship between tarsal bones.

\section{Methods \\ Model establishment}

The geometry of the foot model was reconstructed using the left foot obtained from the Chinese digital human girl No.1 (CDH-G1) image database (specimen of the full-term female infant with body weight of $3.2 \mathrm{~kg}$ and the body length of $39.2 \mathrm{~cm}$, and the slice thickness of $0.1 \mathrm{~mm})$. The contours of the distal tibia and fibular, the whole talus and calcaneus, the cuboids, the navicular, and the five metatarsal were extracted using the software of Photoshop CS3 (Adobe Company, San Jose, CA, USA) and the geometry of these structures was rebuilt with the software of Mimics 17 (Materialise software, Leuven, Belgium). A different threshold limit was chosen to distinguish the cartilage and bone components in the gray-scale images; the operation of segmentation was performed. The 3D geometrical objects were calculated after the segmentation operation, and then imported into the software of Geomagic studio 12 to repair and smooth the irregularity of the model. The geometric model was then converted into the software of Hypermesh 13.0 (Altair Company, Troy, MI, USA) and meshed with tetrahedron elements, and then a solid mesh model was obtained. Finally, the solid mesh model generated from HyperMesh 13.0 was then imported into the software of Abaqus 6.12 (Dassault Systemes Simulia Company, Providence, RI, USA) for finite element analysis.

\section{Material properties}

According to the Ponseti method, clubfoot treatment should be started soon (7 to 10 days) after birth $[6,8]$. The material properties of the model parts were referred to those from the data available in previous literature with a reference to the age. Bones and cartilages in infant foot were idealized as being homogeneous, isotropic, and linearly elastic. The Young's modulus of the bone and cartilage for newborn baby were assigned as $38 \mathrm{MPa}$ and 2.3 $\mathrm{MPa}$, respectively, while the Poisson's ratio was 0.3 for bone and 0.4 for cartilage [16]. In present study, the distal tibia and fibular, and five metatarsal bones were assigned as bone material properties, and the whole talus, calcaneus, three cuboids and navicular bone were assigned as cartilage material properties for the consideration of the infant foot anatomy and radiographic characteristics. The 
ligaments were modeled as linear springs. As reported in the previous studies, the use of linear links to simulate ligaments was found to be adequate $[17,18]$. As no study was found to report the stiffness of ligament in the infant foot, we defined the stiffness of infant foot ligaments based on the adult stiffness in foot ligament and multiple relationships calculated from the research of mechanical properties of cervical spine ligaments between a 14-yearold child and newborn baby [19, 20]. Luck et al. [19] reported that the stiffness of the whole cervical spine (WCS) was $6.8 \mathrm{~N} / \mathrm{mm}$ for the 11-day-old baby and 70.1 $\mathrm{N} / \mathrm{mm}$ for the 14-year-old child. The Achilles tendon stiffness was reported as 306 to $530 \mathrm{~N} / \mathrm{mm}$ in adults [21, 22]. No previous study reported the Achilles tendon stiffness in newborn; we calculated the Achilles tendon stiffness of $40 \mathrm{~N} / \mathrm{mm}$ as normal Achilles tendon stiffness for newborn baby based on data reported previously [19]. The insertion and original sites and the number of ligaments were determined based on anatomical locations and previous literature [20]. A total of 28 ligaments and the Achilles tendon were modeled as linear springs with assigned stiffness values, as shown in Table 1 . The contact behavior between the articulating surfaces was considered frictionless [23] and surface-to-surface contact behavior with the sliding formulation of small sliding [24]. The simulated axis of ankle motion was nearly consistent with the line of medial and lateral malleolus cusp, outward-inclined about $8^{\circ}$ in coronal plane and external rotation about $6^{\circ}$ in transection plane [25]. The micro motion between tarsal bones was ignored in the present study. A mesh convergence study was performed using five different mesh sizes, from 1 to 5 $\mathrm{mm}$. The optimum mesh size for the bone and cartilage was set as $3 \mathrm{~mm}$. The numerical model used in this study contains about 339,310 elements and 69,144 nodes.

\section{Maneuver simulation}

For better illustration of kinematic coupling relationship between tarsal bones, the distal tibia and fibula bone and the head of talus were fixed in all six degrees of freedom during the whole test. Equinus was defined as the increased stiffness of Achilles tendon and increased plantar flexion of the ankle in present finite element

Table 1 Stiffness of ligaments

\begin{tabular}{|c|c|c|}
\hline Ligaments represented in the models & Connected bones & Stiffness $(\mathrm{N} / \mathrm{mm})^{\mathrm{a}}$ \\
\hline Interosseous membrane (4 ligaments) & Tibia-fibula & 40 \\
\hline Anterior tibiofibular (distal) & Tibia-fibula & 7.8 \\
\hline Posterior tibiofibular (distal) & Tibia-fibula & 10.1 \\
\hline Anterior tibiotalar & Tibia-talus & 7 \\
\hline Posterior tibiotalar & Tibia-talus & 8 \\
\hline Tibiocalcaneal & Tibia-calcaneus & 12.2 \\
\hline Tibionavicular & Tibia-navicular & 4 \\
\hline Interosseous talocalcaneal & Talus-calcaneus & 7 \\
\hline Lateral talocalcaneal & Talus-calcaneus & 7 \\
\hline Medial talocalcaneal & Talus-calcaneus & 7 \\
\hline Posterior talocalcaneal & Talus-calcaneus & 7 \\
\hline Anterior talofibular & Talus-fibula & 14.2 \\
\hline Posterior talofibular(2 ligaments) & Talus-fibula & 8 \\
\hline Calcaneofibular ligament & Calcaneus-fibula & 12.7 \\
\hline Dorsal talonavicular (2 ligaments) & Talus-navicular & 7 \\
\hline Calcaneonavicular (dorsal and plantar) & Calcaneus-navicular & 7 \\
\hline Calcaneocuboid (dorsal and short plantar) & Calcaneus-cuboid & 7 \\
\hline Cuboideonavicular (dorsal and plantar) & Cuboid-navicular & 7 \\
\hline Cuneonavicular (dorsal and plantar) & Cuneiforms-navicular & 7 \\
\hline Intercuneiform (dorsal and plantar) & Lateral-intermediate-medial cuneiform & 7 \\
\hline Tarsometatarsal (dorsal and plantar) & Cuneiforms-metatarsals & 7 \\
\hline Metatarsal (dorsal and plantar) & 1st-2nd-3rd-4th-5th metatarsal & 7 \\
\hline Long plantar & Calcaneus-metatarsals & 7 \\
\hline Achilles tendon & - & 40 \\
\hline
\end{tabular}

${ }^{a}$ Calculation based on the foot ligaments stiffness value and multiple relationships according to the cervical ligament parameters reported in 14 -year-old child and newborn baby $[19,20]$ 
model. Earlier PAT was defined as early PAT procedure before forefoot adequate abduction (abducted to $60^{\circ}$ to $70^{\circ}$ without pronation) with ankle dorsiflexion remains less than $10^{\circ}$. The ankle plantar flexion was set at $20^{\circ}$ to simulate the equinus deformity for exploring the role of Achilles tendon. The outward pressure was added on the first metatarsal head to observe the stress distribution and displacement of navicular bone. We defined the magnitude of kinematic coupling of tarsal bones as the displacement shift of each tarsal bone after outward pressure added in present finite element model.

\section{Results}

\section{Validation}

The validation of the established model was to investigate the relationship between the displacement and pressure added on the first metatarsal head (Fig. 1). The displacement of the first metatarsal head was compared between finite element prediction and clinical data collected using mini pressure sensor (measuring range from 0 to about $20 \mathrm{~kg}$, Fig. 1a). The data from the clinical test was collected from the 6 feet in unilateral clubfeet. A linear positive relationship was presented in both groups with the outward pressure added from 1 to $4 \mathrm{~N}$, and deviation was found when the pressure was added from 4 to $6 \mathrm{~N}$ (Fig. 1b). The stress and displacement relationship of the navicular bone was presented in the Fig. 2 . The results of self-validation of finite element model showed that the stress and displacement increased linearly as the pressure added gradually on the first metatarsal head (from 0 to $4 \mathrm{~N}$ ), then the stress and displacement increment of navicular bone (the slope of the line) was gradually reduced as the gradient pressure added on the first metatarsal head from 4 to $7 \mathrm{~N}$ (Fig. 2). The linear increase of stress and displacement was observed with constant slope of line when outward pressure added more than $7 \mathrm{~N}$ (Fig. 2). Also, it was previously reported that the applied force on the first metatarsal was $4.2 \mathrm{~N}$ during the manipulation based on an instrumented clubfoot model [26]. There was the similar stress distribution and intensity on the first metatarsal head (maximum from 4 to $7 \mathrm{~N}$ ) presented in this study.

\section{Stress and displacement distribution for tarsal bones} von Mises stress and displacement distribution of the whole model with the Achilles tendon stiffness of $40 \mathrm{~N} /$ $\mathrm{mm}$ was presented in Fig. 3 under outward pressure of $3 \mathrm{~N}$. The maximum von Mises stress was observed at the navicular, talus and medial malleolus, while the navicular bone was the main stress concentration region (Fig. 3a, b). The maximum displacement was observed at the first metatarsal bone, and the displacement decreased gradient from distal to proximal of whole model (Fig. 3c, d). The minimum displacement of tarsal bones was observed at calcaneus bone. It is indicated that the calcaneus bone had the least kinematic coupling relationship between tarsal bones.

\section{Effect of Achilles tendon}

The relationship between the stiffness of Achilles tendon and the kinematic coupling relationship between tarsal bones was calculated and presented in Fig. 4 at the ankle position of plantar flexion (PF)-20. There was a greater difference in the displacement of navicular bone when the stiffness of Achilles tendon ranged between $0 \mathrm{~N} / \mathrm{mm}$ and any one of others, such as 40,80, 200, 400, and $1000 \mathrm{~N} / \mathrm{mm}$. No difference in the navicular displacement was found in the stiffness of Achilles tendon between 40, $80,200,400$, and $1000 \mathrm{~N} / \mathrm{mm}$ including the outward pressure of $1 \mathrm{~N}, 3 \mathrm{~N}, 5 \mathrm{~N}$, and $10 \mathrm{~N}$. It was supposed that the increased stiffness of Achilles tendon had no influence, while the presence or absence of Achilles tendon had great influence on the kinematic coupling relationship of tarsal bones.

\section{The common effect of ankle position and Achilles tendon} The correlation between the ankle position and the kinematic coupling relationship between tarsal bones was
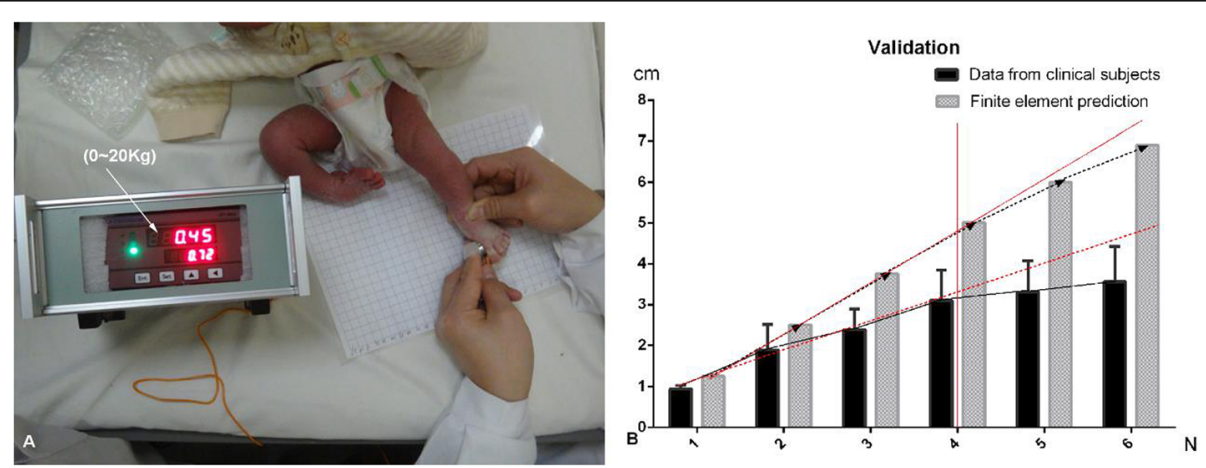

Fig. 1 Outward pressure was measured using mini pressure sensor (a). The validation of the established model was presented in $\mathbf{b}$ (the red line indicates the reference line) 


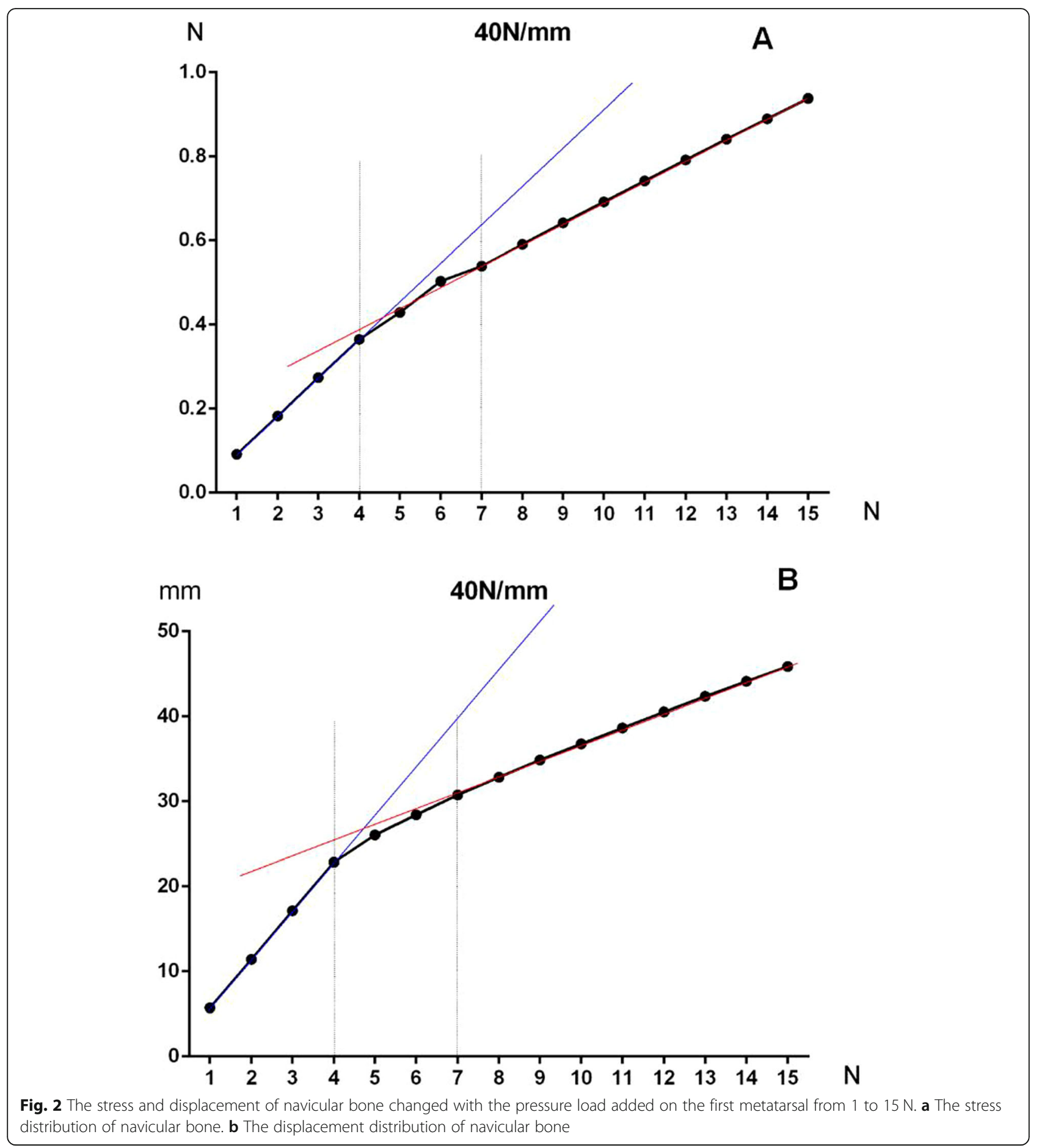

calculated and presented in Fig. 5. The maximum displacement of navicular bone was identified at the ankle position of PF- $20^{\circ}$. In case of the ankle position of $\mathrm{PF}-40^{\circ}$ and dorsiflexion-20 $\left(\mathrm{DF}-20^{\circ}\right.$ ), the displacement of navicular was reduced in comparison with the ankle position of PF-20. Greater displacement of navicular was observed at the Achilles tendon stiffness of $0 \mathrm{~N} / \mathrm{mm}$ than that of $40 \mathrm{~N} / \mathrm{mm}$ at the ankle position of DF- $20^{\circ}$, neutral $-0^{\circ}$ (Neu- $\left.0^{\circ}\right)$ and PF- $20^{\circ}$, while reduced displacement of navicular bone was observed at the ankle position of PF $-40^{\circ}$ with the Achilles tendon stiffness of $0 \mathrm{~N} / \mathrm{mm}$ than $40 \mathrm{~N} / \mathrm{mm}$ (Fig. 5). The displacement of navicular was greater at the ankle position of PF $-40^{\circ}$ with the Achilles tendon stiffness of $40 \mathrm{~N} / \mathrm{mm}$ than $0 \mathrm{~N} / \mathrm{mm}$ (Fig. 6a). However, the decreased displacement of navicular bone was found in the ankle position of PF $-40^{\circ}$ with the Achilles tendon stiffness of $40 \mathrm{~N} / \mathrm{mm}$ than 

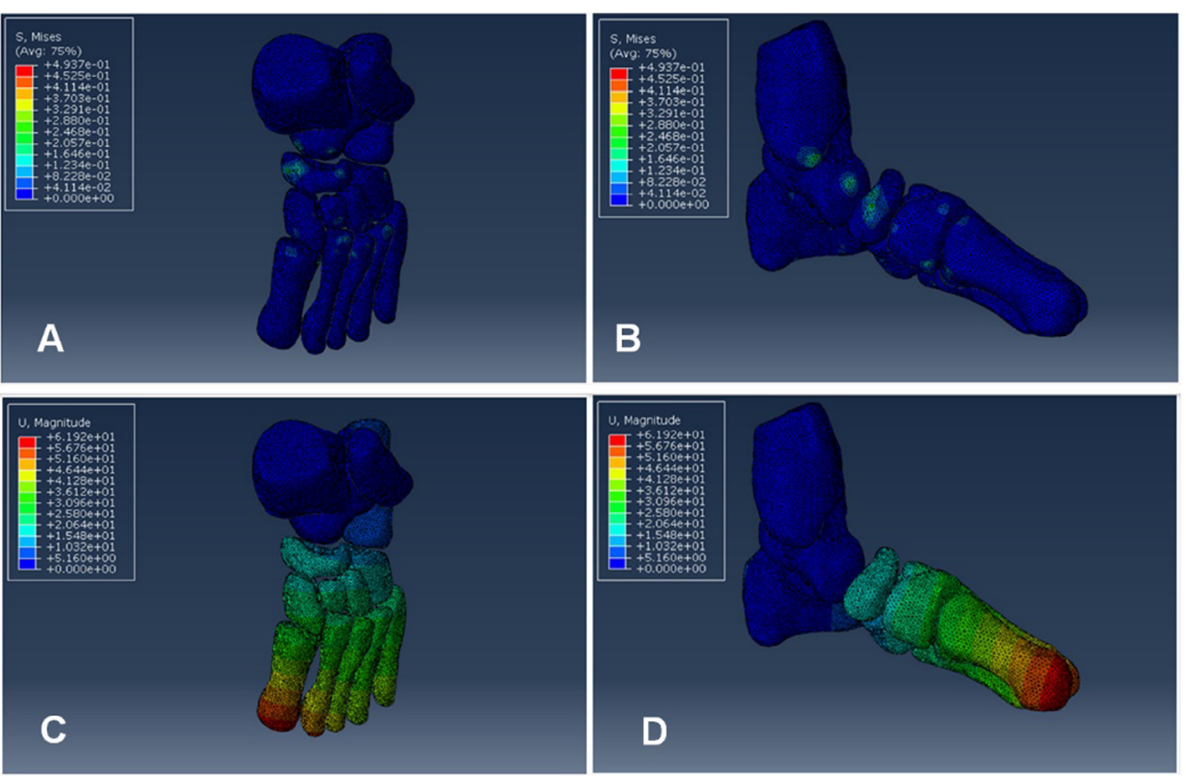

Fig. 3 von Mises stress and displacement distribution was revealed for the whole finite element model. $\mathbf{a}, \mathbf{b}$ The stress distribution of whole foot model. c, d The displacement distribution of whole foot model

the ankle position of PF- $20^{\circ}$ with the Achilles tendon stiffness of $0 \mathrm{~N} / \mathrm{mm}$ (Fig. 6b). It was supposed that earlier implementation of PAT procedure to reduce the degree of ankle plantar flexion may enhance kinematic coupling relationship of tarsal bones in case of severe equinus deformity.

\section{Discussions}

Equinus deformity was an important component of clubfoot deformity and contracture of Achilles tendon contributed greatly to this deformity. The kinematic coupling relationship between tarsal bones was core principle for simultaneous correction of multiple deformity components [5, 6]. In some cases of clubfoot with severe equinus deformity, some authors recommended the posterior capsulotomy to obtain adequate correction for these challenging cases at the sagittal plane $[27,28]$. Therefore, we have to reevaluate the role of Achilles tendon in the Ponseti method for the clubfoot management. Unfortunately, little was known about the
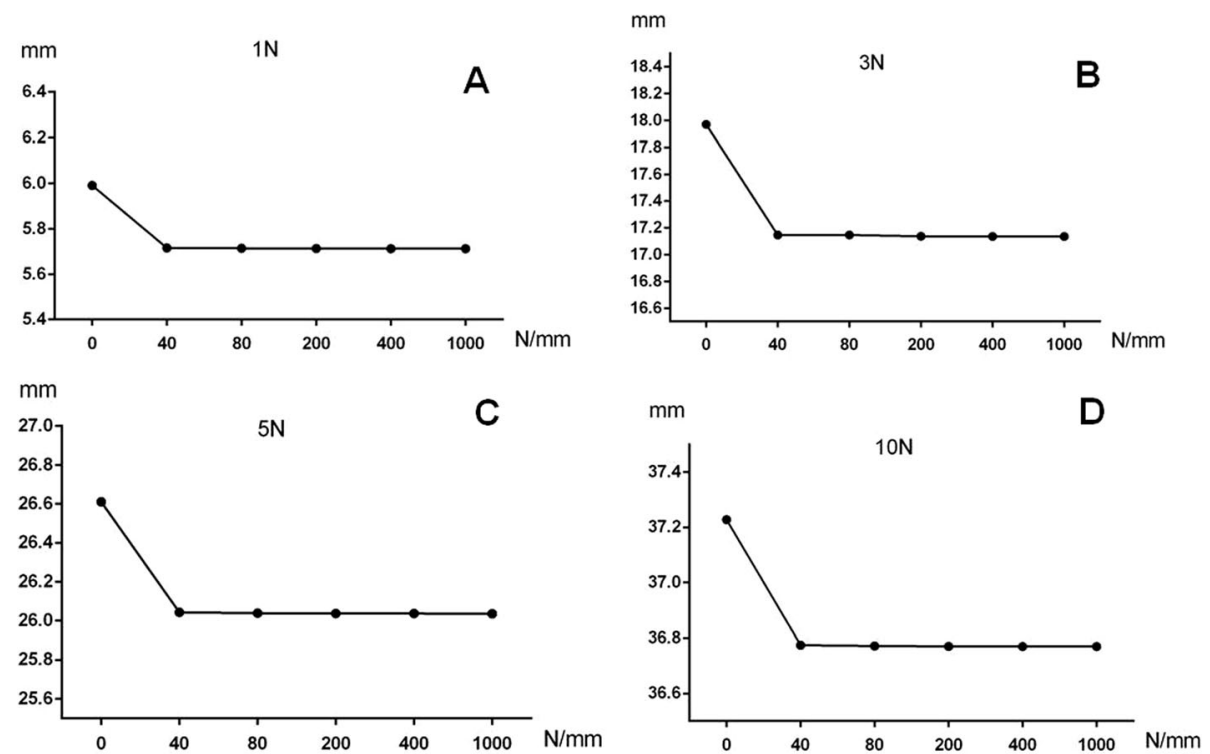

Fig. 4 Greater difference was found in the navicular displacement with Achilles tendon between $0 \mathrm{~N} / \mathrm{mm}$ and anyone of others. Increased stiffness of Achilles tendon seemed to have no influence on the displacement of navicular bone 

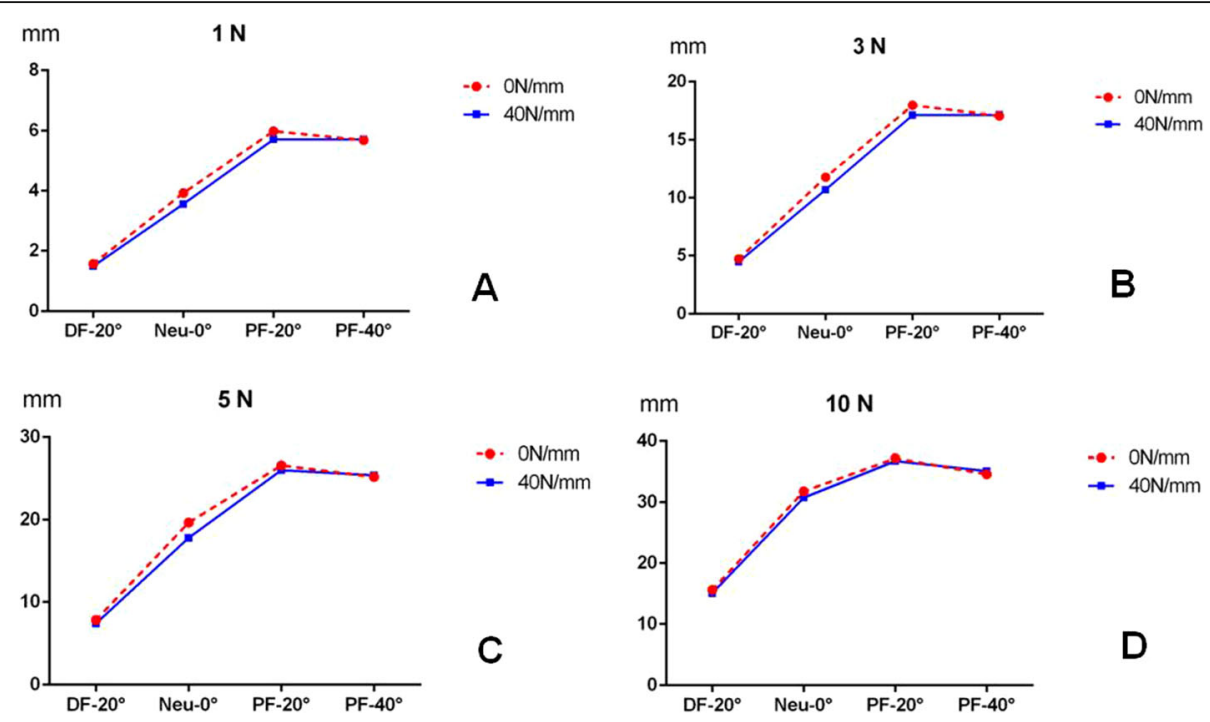

Fig. 5 The common effect of ankle position and Achilles tendon was presented. The maximum displacement of navicular bone was observed at the ankle position of PF-20

correlation between Achilles tendon and kinematic coupling relationship between tarsal bones. For further exploring the intrinsic mechanism for the role of the Achilles tendon in the kinematic coupling relationship between tarsal bones, the CDH-G1 image database was applied to establish the 3D foot model and to understand the effect of the of Achilles tendon in response to the Ponseti maneuver.

The finite element model was validated mainly using the data from cadaveric experiment with similar settings, published studies data or self-validation of established model for the comparison [29-31]. To our knowledge, no previous studies have reported the biomechanics of simulated Ponseti maneuver in terms of either cadaveric experiment or finite element analysis. The established model of present study was validated and compared to the clinical data collected from 6 unilateral clubfoot cases tested using mini pressure sensor. The results showed that practical manipulation was well simulated in the finite element model under the pressure added less than $4 \mathrm{~N}$, while variation of displacement was found under the pressure load added from 4 to $6 \mathrm{~N}$. This may be attributed to the simplification of the established model. The ligaments in the present study were simulated as linear springs, and the influence of capsule and muscle in the foot was disregarded in present study. These differences lead to the absence of "transitional phase" and replacement of reduced increment of displacement (slope of the line) in finite element model. The stress and displacement of navicular bone revealed that the pressure added on the first metatarsal head from 4 to $7 \mathrm{~N}$ was an important "transitional phase" for the clinical effectiveness in the process of Ponseti maneuver. It was supposed that the maximum stress may range from 4 to $7 \mathrm{~N}$ to avoid the injury of soft tissues. Also, it was previously reported that the applied force on the first metatarsal was $4.2 \mathrm{~N}$ during the manipulation based on an instrumented clubfoot model [26]. There was the similar stress distribution and intensity on the first metatarsal head (maximum from 4 to $7 \mathrm{~N}$ ) presented in this study.

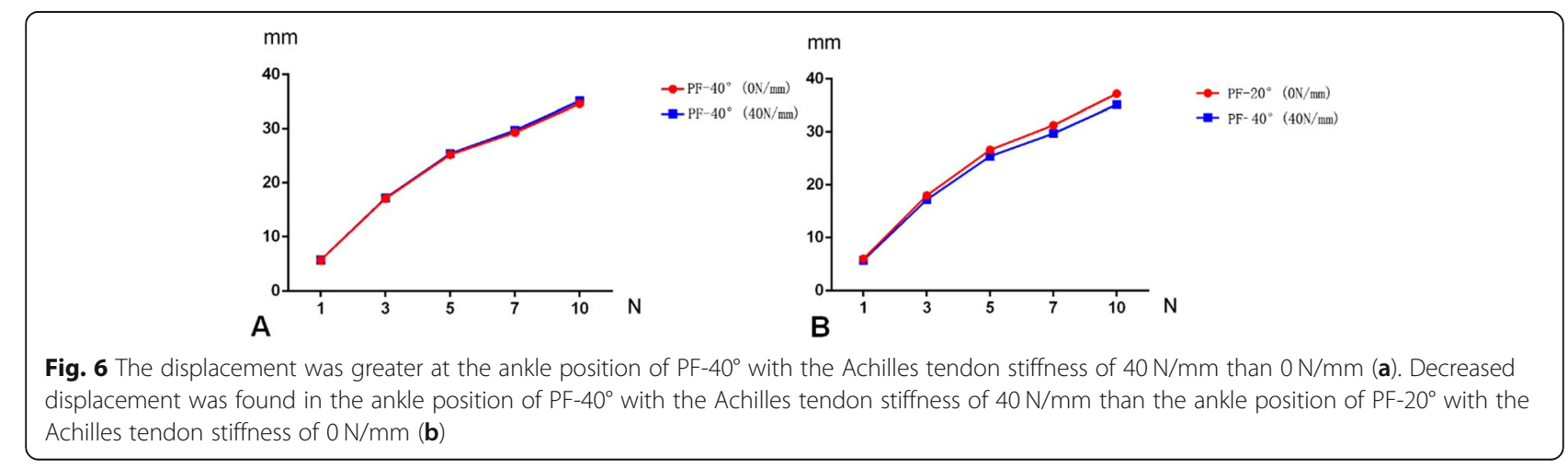


The maximum stress distribution was found to be mainly concentrated on the talus and navicular. This supposedly means that talonavicular joint was the most important articulation for deformity correction during the process of Ponseti maneuver. The pathoanatomy of clubfoot showed that the navicular bone was wedgeshaped and medially displaced, while the medial tuberosity of the navicular was approached to the medial malleolus [6, 7]. As reported by Pirani et al [32], the correction by means of the Ponseti method included not only the relocation of the abnormal relationships between the tarsal bones, but also the remodeling of the individual tarsal osteochondral anlages. In present study, the stress concentration was found on the navicular bone when outward pressure was added. The maximum stress distribution was mainly focused on the insertion of tibionavicular ligaments. This presumably indicates that the manipulation in the Ponseti method has mainly contributed to stretching the tibionavicular ligament. This was consistent with the findings in the pathoanatomy of clubfoot that the tibionavicular ligament was very thick and short $[3,5,6]$. The kinematic coupling relationship was observed in that calcaneus, cuboid, three cuneiform, and five metatarsal bones simultaneously moved laterally as the outward pressure added on the first metatarsal head. This presumably explains that Ponseti maneuver was an appropriate and effective way to correct all the deformity components. The minimum displacement was observed at calcaneus bone, which indicated that the calcaneus bone had the least movement in response to the kinematic coupling relationship of tarsal bones. Herein, it was recommended that the forefoot should be abducted adequately to correct the hind-foot varus in clinical practice.

The effect of Achilles tendon revealed that the navicular displacement at the Achilles tendon stiffness of $0 \mathrm{~N} /$ $\mathrm{mm}$ was greater than that of 40,80,200,400, and 1000 $\mathrm{N} / \mathrm{mm}$. Also, the decreased displacement of navicular bone was found in the ankle position of PF- $40^{\circ}$ with the Achilles tendon stiffness of $40 \mathrm{~N} / \mathrm{mm}$ than the ankle position of PF- $20^{\circ}$ with the Achilles tendon stiffness of 0 $\mathrm{N} / \mathrm{mm}$. In clinical practice, it was easy to understand that the PAT procedure had the effect not only on the existence of Achilles tendon but also on the ankle position. Based on the results, it was supposed that earlier implementation of PAT procedure may enhance the kinematic coupling relationship of tarsal bones and facilitate the deformity correction. The common effects of Achilles tendon and ankle position revealed that more displacement of navicular bone was observed at the ankle position of $\mathrm{PF}-20^{\circ}$ compared with that at the ankle position of Neu- $0^{\circ}$ and PF- $40^{\circ}$ (Fig. 5). It is supposed that the most effective position of kinematic coupling relationship of tarsal bones may be related to the ankle position of PF- $20^{\circ}$. The explanation may be attribute to the "locks and unlocks mechanism" between transverse tarsal joint. When the ankle position was set to Neu- $0^{\circ}$ and $\mathrm{DF}-20^{\circ}$, more stability of the ankle was triggered for the locking of transverse tarsal joint. The kinematic coupling relationship of tarsal bones was disturbed because of the stability of the ankle. The reduced displacement was also found in the ankle position $\mathrm{PF}-40^{\circ}$, which may be caused to the excessive unlock of transverse tarsal joint, and then reduced the kinematic coupling relationship of tarsal bones. The stiffness of Achilles tendon stiffness in $0 \mathrm{~N} / \mathrm{mm}$ had more navicular displacement than that of $40 \mathrm{~N} / \mathrm{mm}$ at the positions of DF- $20^{\circ}$, Neu- $0^{\circ}$ and PF- $20^{\circ}$, while no benefit was obtained for the ankle position of $\mathrm{PF}-40^{\circ}$. It was supposed that the effectiveness of kinematic coupling relationship between tarsal bones may benefit from earlier implementation of PAT procedure at the positions of DF- $20^{\circ}$, Neu- $0^{\circ}$, and $\mathrm{PF}-20^{\circ}$, except for the ankle position of PF- $40^{\circ}$. However, the equinus deformity was corrected from quite severe to less severe position using the protocol of earlier PAT procedure (for example, less than $\mathrm{PF}-20^{\circ}$ ), the manipulation effectiveness may be enhanced (Fig. 6). This was consistent with clinical experience that it was difficult to correct the severe equinus deformity $\left(\mathrm{PF}-40^{\circ}\right)$ in some challenging case before the procedure of PAT.

The merit of present study was that the effects of Achilles tendon and the kinematic coupling relationship of tarsal bones were firstly demonstrated in terms of finite element method. The geometry of the foot and ankle model was reconstructed from $\mathrm{CDH}-\mathrm{G} 1$ image database, which had better recognized contour of foot cartilage and bone than that of magnetic resonance imaging (MRI), and provided more and precise information of foot tarsal bone in newborn. The incidence of clubfeet is higher in male. The established model may be better from the Chinese digital human boy. However, the aim of preset study was to focus on the kinematics of relationship between Achilles tendon and tarsal bones, not on the biology of the deformity. The contours of tarsal bone were extracted and ligaments were modeled as linear springs for the established model in present study. So, we think there was little or no deviation to the results. Another limitation was that we applied the normal foot model in a newborn to simulate the Ponseti maneuver; the variance did exist between clubfoot and normal foot model. However, we know that the clubfoot could be considered the normal foot after the Ponseti method correction [3-6]. The context of model simplifications and settings in present study was another limitation. We only extracted the information of cartilage and bone to build the 3-D foot model, and the Achilles tendon and ligaments were modeled with springs that may result in stress concentration at the insertions. 
In conclusion, it was demonstrated that Achilles tendon has great effect on kinematic coupling relationship between tarsal bones, and the least kinematic coupling relationship between tarsal bones was found in the calcaneus. The increased stiffness of Achilles tendon had no influence on kinematic coupling relationship between tarsal bones. The ankle position of PF- $20^{\circ}$ was the effective position where the kinematic coupling relationship of tarsal bones was revealed. For the cases with severe equinus, earlier implementation of PAT procedure, with the purpose of releasing the Achilles tendon and reducing the degree of ankle plantar flexion, may be beneficial to the deformity correction.

\section{Abbreviations}

PAT: Percutaneous Achilles tenotomy; $\mathrm{CDH}-\mathrm{G} 1$ : Chinese digital human girl No.1; PF: Plantar flexion; DF: Dorsiflexion-20; Neu: Neutral; MRI: Magnetic resonance imaging

\section{Authors' contributions}

YB Liu and SJ Li contributed to the design and concept of the study. L Tang contributed to the design of the validation of the FEA model and critical recommendation for the established model, and provided the Chinese digital human girl No.1 (CDH-G1) image database for present study. L Zhao and CL Liu contributed to data analysis and interpretation. All authors contributed to the writing and critical revisions for intellectual content and final approval of the article.

\section{Funding}

This study was funded by National Natural Science Foundation of China (No. 81802215).

\section{Availability of data and materials}

The datasets used and/or analyzed during the current study are available from the corresponding author on reasonable request.

\section{Ethics approval and consent to participate}

The Chinese digital human girl No.1 (CDH-G1) image database was applied for the establishment of foot and ankle model. This article does not contain any studies with human participants or animals performed by any of the authors.

\section{Consent for publication}

Not applicable.

\section{Competing interests}

All authors declare that they have no competing interests.

\section{Author details}

'Department of Orthopaedics, Zhujiang Hospital of Southern Medical University, Guangzhou 510280, China. ${ }^{2}$ Department of Anatomy, Southern Medical University, Guangzhou 510280, China. ${ }^{3}$ Ying-Hua Medical Group of Bone and Joint Healthcare in Children, Shanghai 200092, China.

Received: 13 March 2020 Accepted: 25 May 2020

Published online: 08 June 2020

\section{References}

1. Liu YB, Li SJ, Zhao L, Yu B, Zhao DH. Timing for Ponseti clubfoot management: does the age matter? 90 children (131 feet) with a mean follow-up of 5 years. Acta Orthop 2018;89(6):662-667.https://doi:https://doi. org/10.1080/17453674.2018.1526534.

2. Liu YB, Jiang SY, Zhao L, Yu Y, Zhao DH. Can repeated Ponseti management for relapsed clubfeet produce the outcome comparable with the case without relapse? A clinical study in term of gait analysis. J Pediatr Orthop 2020;40(1):29-35.https://doi:https://doi.org/10.1097/bpo.0000000000001071.
3. Liu Y, Zhao D, Zhao L, Li H, Yang X. Congenital clubfoot: early recognition and conservative management for preventing late disabilities. Indian J Pediatr 2016;83(11):1266-1274.https://doi:https://doi. org/10.1007/s12098-015-1860-x.

4. Zhao D, Liu J, Zhao L, Wu Z. Relapse of clubfoot after treatment with the Ponseti method and the function of the foot abduction orthosis. Clin Orthop Surg 2014;6(3):245-252.https://doi:https://doi.org/10.4055/ cios.2014.6.3.245.

5. Ponseti IV. Common errors in the treatment of congenital clubfoot. Int Orthop 1997;21(2):137-141.https://doi:https://doi.org/10.1007/ s002640050137.

6. Ponseti IV. Congenital clubfoot: fundamentals of treatment. Oxford, New York: Oxford University Press; 1996.

7. Ponseti IV, Smoley EN. The classic: congenital club foot: the results of treatment. 1963. Clin Orthop Relat Res 2009;467(5):1133-1145.https://doi: https://doi.org/10.1007/s11999-009-0720-2.

8. Zhao D, Li H, Zhao L, Liu J, Wu Z, Jin F. Results of clubfoot management using the Ponseti method: do the details matter? A systematic review. Clin Orthop Relat Res 2014;472(4):1329-1336.https://doi:https://doi.org/10.1007/ s11999-014-3463-7.

9. Richards BS, Faulks S, Rathjen KE, Karol LA, Johnston CE, Jones SA. A comparison of two nonoperative methods of idiopathic clubfoot correction: the Ponseti method and the French functional (physiotherapy) method. J Bone Joint Surg Am 2008;90(11):2313-2321.https://doi:https://doi.org/10. 2106/jbjs.g.01621.

10. Lourenco AF, Morcuende JA. Correction of neglected idiopathic club foot by the Ponseti method. J Bone Joint Surg Br. 2007;89B(3):378-381.https:// doi:https://doi.org/10.1302/0301-620x.89b3.18313.

11. Agarwal A, Kumar Kh V. What to do when percutaneous Achilles tenotomy fails in Ponseti technique? J Pediatr Orthop B 2018;27(5):472.https://doi: https://doi.org/10.1097/bpb.0000000000000521.

12. Parsa $\mathrm{A}$, Moghadam $\mathrm{MH}$, Jamshidi $\mathbf{M H}$. Relapsing and residual clubfoot deformities after the application of the ponseti method: a contemporary review. The archives of bone and joint surgery 2014;2(1): 7-10.https://doi:undefined.

13. Park SS, Lee HS, Han SH, Park JW, de Peralta MJ. Gastrocsoleus fascial release for correction of equinus deformity in residual or relapsed clubfoot. Foot Ankle Int 2012;33(12):1075-1078. https://doi:https://doi. org/10.3113/fai.2012.1075

14. Mehtani A, Prakash J, Vijay V, Kumar N, Sinha A. Modified Ponseti technique for management of neglected clubfeet. Journal of pediatric orthopedics Part B. 2018;27(1):61-66.https://doi:https://doi.org/10.1097/bpb. 0000000000000450

15. Agarwal A, Agrawal N, Barik S, Gupta N. Extended Ponseti method for failed tenotomy in idiopathic clubfeet: a pilot study. J Pediatr Orthop B 2018;27(5): 425-427.https://doi:https://doi.org/10.1097/bpb.0000000000000509.

16. Tsai A, Coats B, Kleinman PK. Stress profile of infant rib in the setting of child abuse: a finite element parametric study. J Biomech 2012;45(11):18611868.https://doi:https://doi.org/10.1016/j.jbiomech.2012.05.049.

17. Bajuri MN, Kadir MR, Raman MM, Kamarul T. Mechanical and functional assessment of the wrist affected by rheumatoid arthritis: a finite element analysis. Med Eng Phys 2012;34(9):1294-1302.https://doi:https://doi.org/10. 1016/j.medengphy.2011.12.020

18. Yu J, Cheung JT, Fan Y, Zhang Y, Leung AK, Zhang M. Development of a finite element model of female foot for high-heeled shoe design. Clin Biomech (Bristol, Avon). 2008;23 Suppl 1:S31-S38.https://doi:https://doi.org/ 10.1016/j.clinbiomech.2007.09.005.

19. Luck JF, Nightingale RW, Loyd AM, Prange MT, Dibb AT, Song Y, et al. Tensile mechanical properties of the perinatal and pediatric PMHS osteoligamentous cervical spine. Stapp Car Crash J. 2008:52:107-34

20. Ramlee MH, Kadir MR, Murali MR, Kamarul T. Biomechanical evaluation of two commonly used external fixators in the treatment of open subtalar dislocation--a finite element analysis. Med Eng Phys 2014;36(10):1358-1366. https://doi:https://doi.org/10.1016/.j.medengphy.2014.07.001.

21. Rosager S, Aagaard P, Dyhre-Poulsen P, Neergaard K, Kjaer M, Magnusson SP. Load-displacement properties of the human triceps surae aponeurosis and tendon in runners and non-runners. Scand J Med Sci Sports 2002;12(2): 90-98.https://doi:https://doi.org/10.1034/j.1600-0838.2002.120205.x.

22. Reeves ND, Maganaris CN, Narici MV. Effect of strength training on human patella tendon mechanical properties of older individuals. J Physiol 2003: 548(Pt 3):971-981.https://doi:https://doi.org/10.1113/jphysiol.2002.035576. 
23. Eberhardt AW, Lewis JL, Keer LM. Contact of layered elastic spheres as a model of joint contact: effect of tangential load and friction. J Biomech Eng 1991;113(1):107-108.https://doi:https://doi.org/10.1115/1.2894076.

24. Chen YN, Chang CW, Li CT, Chang CH, Lin CF. Finite element analysis of plantar fascia during walking: a quasi-static simulation. Foot Ankle Int 2015; 36(1):90-97.https://doi:https://doi.org/10.1177/1071100714549189.

25. Zwipp H. Biomechanics of the ankle joint. Unfallchirurg. 1989;92(3):98-102.

26. Giesberts RB, Hekman EE, Maathuis PG, Verkerke GJ. Quantifying the Ponseti method. J Mech Behav Biomed Mater 2017;66:45-49.https://doi:https://doi. org/10.1016/j.jmbbm.2016.10.021.

27. Fujak A, Forst R, Forst J. Outcome after Achilles tendon lengthening with a posterior capsulolysis according to Imhauser in idiopathic congenital clubfoot. Ortop Traumatol Rehabil. 2008;10(4):367-76.

28. Jauregui JJ, Zamani S, Abawi HH, Herzenberg JE. Ankle range of motion after posterior subtalar and ankle capsulotomy for relapsed equinus in idiopathic clubfoot. J Pediatr Orthop 2017;37(3):199-203.https://doi:https:// doi.org/10.1097/bpo.0000000000000611.

29. Funk JR, Crandall JR, Tourret LJ, MacMahon CB, Bass CR, Patrie JT, Khaewpong N, Eppinger RH. The axial injury tolerance of the human foot/ ankle complex and the effect of Achilles tension. J Biomech Eng 2002; 124(6):750-757.https://doi:https://doi.org/10.1115/1.1514675.

30. Wong DW, Niu W, Wang Y, Zhang M. Finite element analysis of foot and ankle impact injury: risk evaluation of calcaneus and talus fracture. PLoS One 2016;11(4):e0154435.https://doi:https://doi.org/10. 1371/journal.pone.0154435.

31. Alberts LR, Phillips KO, Tu HK, Stinson WW, Friedman A. A biologic model for assessment of osseous strain patterns and plating systems in the human maxilla. J Oral Maxillofac Surg 2003;61(1):79-88.https://doi:https://doi.org/10. 1053/joms.2003.50013.

32. Pirani S, Zeznik L, Hodges D. Magnetic resonance imaging study of the congenital clubfoot treated with the Ponseti method. J Pediatr Orthop 2001; 21 (6):719-726.https:/doi:https://doi.org/10.1097/00004694-200111000-00004.

\section{Publisher's Note}

Springer Nature remains neutral with regard to jurisdictional claims in published maps and institutional affiliations.

Ready to submit your research? Choose BMC and benefit from:

- fast, convenient online submission

- thorough peer review by experienced researchers in your field

- rapid publication on acceptance

- support for research data, including large and complex data types

- gold Open Access which fosters wider collaboration and increased citations

- maximum visibility for your research: over $100 \mathrm{M}$ website views per year

At $\mathrm{BMC}$, research is always in progress.

Learn more biomedcentral.com/submissions 